\title{
BESSETER RAAM DE MÊNDELE MOCHER SFÓRIM E O RENASCIMENTO DA LÍNGUA HEBRAICA
}

\author{
Gabriel Steinberg*
}

\section{Resumo}

O surgimento da Haskalá no final do século XVIII foi o fato que possibilitou o renascimento da literatura hebraica de caráter secular e que, posteriormente, permitiu o renascimento do hebraico falado na Terra de Israel. Os escritores da Haskalá enriqueceram a língua com novas palavras e expressões e a aproximaram da modernidade. Foi o escritor Mêndele Mocher Sfórim que, ao utilizar um estílo eclético, ajudou a transformar o hebraico em idioma literário, retirando-o do pedestal de sacralidade em que se encontrou durante 1800 anos.

Palavras-chave: Haskalá, Mêndele Mocher Sfórim, Sionismo, língua hebraica, literatura hebraica.

\begin{abstract}
The emergence of Haskalah in the late eighteenth century, was the fact that enabled the revival of Hebrew literature and secularization of the language which later allowed the revival of spoken Hebrew in the Land of Israel. The writers of Haskalah, enriched the language with new words and expressions and brought it to modernity. It was the writer Mendele Mocher Sforim that when using an eclectic style, helped to transform the Hebrew in literary language, by removing the Hebrew language from the sacred character that prevailed for 1800 years.
\end{abstract}

Keywords: Haskalah, Mendele Mocher Sforim, Zionism, the Hebrew language, Hebrew literature.

* Professor Doutor de Língua Hebraica do Departamento de Letras Orientais da Faculdade de Filosofia, Letras e Ciências Humanas da Universidade de São Paulo. <steinberg1818@ hotmail. com> 
O surgimento da Haskalál, o movimento do iluminismo judaico no final do século XVIII, foi o fato que desencadeou o renascimento da literatura hebraica de caráter secular fato este que possibilitou posteriormente, dar um novo impulso ao hebraico falado na Terra de Israel. O despertar político e cultural que os povos europeus vivenciavam na época, incluía a valorização de suas línguas populares além da elevação da língua à função de cultura, ampliando-a para atender às necessidades lingüísticas da modernidade. Os judeus inseridos nos embates nacionalistas na Europa, também se viram na necessidade de criar um movimento que lhes permitisse adentrar como iguais na cultura européia. Para tanto, era preciso fazer renascer a língua que durante séculos deixou de ser utilizada na comunicação diária, desde o início da dispersão do povo no século II da Era Comum. No século XIX, os escritores da Haskalá enriqueceram o hebraico com novas palavras e expressões e o aproximaram à modernidade. A criação de jornais hebraicos na mesma época foi de vital importância para mostrar ao povo judeu na Europa, que era possível transformar a língua ancestral numa língua mais dinâmica e própria a tratar de assuntos do cotidiano. Ao mesmo tempo para a liderança do movimento sionista, e em especial para Theodor Herzl, o hebraico não tinha condições de ser o idioma do futuro estado que ele apregoava. Para Herzl a língua não era um elemento constitutivo da identidade judaica.

A Haskalá se caracterizou por ser um movimento cultural elitista de judeus que queriam aproximar-se da cultura ocidental, fenômeno que ocorreu com maior força na Alemanha e na Rússia, e concomitantemente, recriar a língua antiga e modernizá-la. Fazer renascer a língua do passado, sigificava evocar a época em que os judeus tiveram seu estado nacional e, por conseguinte, uma existência criativa politica e cultural plena. Este era um dos requisitos dos judeus modernos necessário para poder se equiparar aos povos da Europa. No século XIX surgiram pequenos grupos de intelectuais judeus influneciados pelo iluminismo europeu e pela Revolução Francesa que queriam transformar a língua bíblica em veículo de expressão, em língua de comunicação corrente. As idéias modernas não podiam ser expressas no hebraico conhecido na época, e empregar o hebraico bíblico para expressar idéias novas parecia uma tarefa difícil e limitante. Mesmo assim, os escritores e intelecuais iluministas começaram a utilizar a retórica e o hebraico da Bíblia para expressar as idéias de sua época. Este estilo literário foi chamado Sfat Hamelitsá ${ }^{2}$, ou seja, um método de línguagem que empregava trechos e versículos bíblicos fazendo com os mesmos um shibutz, a incrustação e inserção desses trechos em seus escritos.

Os homens da Haskalá desejavam afastar-se do judaísmo rabínico normativo e do ídiche que era a língua do gueto e a seus olhos, um jargão que remetia à humilhação do povo em séculos de disperssão. Eles concluíram que era preciso recriar uma literatura em língua

\footnotetext{
${ }^{1}$ Haskalá - Designa o movimento da Ilustração judaica iniciado na Alemanha na segunda metade do século XVIII tendo como figura principal o filósofo Moses Mendelsshon.

${ }^{2}$ Segundo Nancy Rozenchan: "A linguagem poética da literatura hebraica da Haskalá baseou-se em dois princípios centrais: purismo e melitsá (frase florida). O purismo era um princípio pelo qual somente eram utilizadas palavras existentes no texto bíblico, mesmo que não em sentido literal. A melitsá era uma combinação de frases da Bíblia. Na transposição de uma citação do texto original para um novo, o significado do contexto original podia ser mantido, alterado ou subvertido" (Mêndele Môikher Sfórim. O Homenzinho, p. 16 - Apresentação).
} 
hebraica e por isso o hebraico bíblico mesmo que limitante e não a língua dos sábios, o hebraico mishnaico que surgiu no retorno da Babilônia e na época do segundo Templo com forte influência do aramaico, era digno de ser utilizado na nova criação literária. Os escritores do século XIX pregavam por um purismo na utilização da linguagem e na melitsá, que como foi mencionado era a recriação do estilo bíblico com a citação do original de palavras, versículos ou trechos escritos no mesmo estilo. Quanto maior a quantidade de citações de trechos bíblicos, mais elevada era considerada a escrita. Um dos mais destacados escritores deste período foi Avraham Mapu (1807 - 1867) que, ao publicar seu primeiro romance em língua hebraica, chamado Ahavat Tsion (O Amor a Sion), publicado em 1853, causou grande repercussão e no qual se percebe o estrato bíblico por excelência:

Havia um homem em Jerusalém nos dias de Hachaz rei de Yehudá e seu nome era Yoram Ben Aviezer, comandante em Yehudá. E ele possuia campos e vinhedos no Monte Carmelo e na região do Sharon e rebanhos de carniros e gado em Beit Lechem Yehudá. E ele tinha ainda prata e ouro, e duas esposas ele tinha, o nome da primeira era Chaguit filha de Hirá, e o nome da segunda era Naamá. E amou Yoram a Naamá, pois ela era de bela feição. E invejou-a Chaguit e a atormentou, pois Chaguit tinha dois filhos, mas Naamá não tinha nenhum. Porém Naamá era agradável em sua aparência e comportamento e para ela Yoram construiu uma casa, para que esta não fosse molestada por Chaguit, sua atormentadora. ${ }^{3}$

Theodor Herzl, o fundador do sionismo político por outro lado, não acreditava que fosse possível sequer cogitar a idéia de transformar o hebraico em língua falada, muito menos que esta poderia tornar-se a língua de comunicação corrente no futuro país dos judeus. $\operatorname{Em} O$ Estado Judeu, de 1896, ele afirmava sua incredulidade em aceitar a possibilidade de um renascimento do hebraico, e ainda propunha um arranjo natural que se daria entre todas as línguas faladas pelos judeus da época, excluíndo, é claro, o ídiche, ao afirmar que num futuro não distante, uma das línguas haveria de prevalecer, tornando-se aceita por todos. Assim ele diz:

Talvez alguém opine que haverá um grande inconveniente em que não tenhamos ainda um idioma comum. Haveremos de falar hebraico? Quem, entre nós, sabe hebraico suficiente para pedir um bilhete de trem? Não há quem saiba fazê-lo. Contudo, a coisa é bem simples. Cada um conservará seu idioma, idioma de sua pátria. A Suíça constitui um exemplo definitivo da possibilidade de um federalismo lingüístico. Nos desacostumaremos dos miseráveis e tortuosos jargões, idiomas do gueto, dos quais nos servimos até agora. Estes eram o modo de falar clandestino de prisioneiros. Nossos professores estudarão atentamente esta questão. O idioma que vier a ser o mais útil na vida cotidiana, será imposto, sem violência, como idioma principal. A comunidade do

\footnotetext{
${ }^{3}$ Disponível em: http://benyehuda.org/mapu/ahavat_zion_complete.html <Acesso em 30/09/2012>. Neste texto percebe-se uma semelhança com a narrativa bíblica que se refere ao nascimento do profeta Samuel conforme aparece narrado em Samuel I, capítulo 1, versículos 1 - 6.
} 
nosso povo é, por certo, muito singular. Na realidade, nos reconhecemos como pertencentes ao mesmo povo somente pela fé de nossos pais. (HERTZL, 1998, p. 104)

Foi graças a escritores influenciados pela Haskalá como Mêndele Mocher Sfórim, pseudônimo de Shálom Yákov Abramovitsh (1835 - 1917), que ao utilizar um estílo eclético, transformaram o hebraico num idioma literário. Ao distanciar-se da cultura religiosa, Mêndele se valeu tanto do hebraico bíblico como do hebraico da Mishná para criar sua prosa, aproximando a língua semiadormecida de seu público leitor. Mêndele quebrou o modelo limitador ao usar o estrato bíblico e mishnaico concomitantemente. Nascido em Minsk na atual Belarus, é considerado um dos fundadores da moderna literatura ídiche e hebraica. Mêndele viveu no período de transição entre a Haskalá e o renascimento do hebraico falado na passagem do século XIX para o seguinte. Na época, os judeus do Leste da Europa estavam confinados na Área de Residência ou de assentamento, o chamado Pale. Eles também eram proibidos de habitar as áreas rurais e encontravam-se ameaçados constantemente por leis restritivas impostas pelo Czar da Rússia. Mêndele era um judeu ocidentalizado que cortou os laços com a religião e era aberto aos ventos da emancipação. Era um representante do modelo intelectual dos judeus lituanos já que a Belarus fazia parte nesse então da Lituânia histórica.

Ao lançar-se à escrita, sentiu-se limitado pelo modelo da melitsá e do shibutz e decidiu escrever em ídiche. Ele desenvolveu a literatura moderna nessa língua inicialmente. $\mathrm{O}$ ídiche visto por muitos como um jargão, era encarado como uma língua sem ilustração literária, era a língua do povo, uma língua considerada baixa ao contrário do hebraico considerado a língua da alta cultura. Mêndele fez um esforço considerável ao tentar enobrecer o ídiche dando a esta língua um elevado padrão literário. No meio termo, se cansou do ídiche e decidiu retornar ao hebraico só que ao retornar, ele vai escrever num hebraico libertado das amarras bíblicas, um hebraico com marcante influência do ídiche. Foi ele o primeiro a ousar e a usar na literatura, os três estratos do hebraico conhecidos até então: o bíblico, o mishnaico e o medieval além de influência do russo e do ucraniano (ASLANOV, 2012, p. 84). Ele adotou um estílo eclético, com formações sintâticas onde se reconhece a influência do ídiche na escrita hebraica. Esta etapa concidiu com sua mudança para Odessa ${ }^{4}$ que era o centro nevrálgico do movimento da Haskalá no Leste da Europa. Mêndele viveu nesta cidade até sua morte em 1917.

Mêndele pretendia inicialmente ecrever em hebraico da mesma forma como se falava. Porém naquela época eram poucas as pessoas na Europa capazes de falar hebraico. Havia alguns intelectuais que influenciados pela Haskalá tentavam falar hebraico a partir do acervo

\footnotetext{
${ }^{4}$ Odessa - Cidade portuária ucraniana às margens do Mar Negro. No século XIX era a terceira cidade mais importante do Império Russo atrás apenas de Moscou e São Petersburgo. Os judeus se estabeleceram na cidade no século XIX quando esta se tornou um porto livre. Calcula-se que a população judaica somava mais de 160 mil pessoas no final do século, o que a tornou na maior cidade de população judaica do Império. Os judeus sofreram vários pogroms em 1881 e 1905. No final do século XIX se consolidou na cidade o movimento do iluminismo judaico, e muitos judeus passaram a freqüentar escolas e universidades e também foi fundada ali uma escola judaica moderna. Também nessa época foi fundado um centro de apoio ao movimento sionista, e Odessa se transformou numa importante base de atuação do movimento nacionalista judaico. Foi ali também que atuaram os grandes escritores sionistas e pioneiros da moderna literatura hebraica como Bialik e Klausner.
} 
que tinham da escrita e da leitura. Eles falavam então como se escrevia, mas o resultado não mostrava ser uma fala natural e muito menos espontânea. O mérito de Mêndele foi ter libertado o hebraico das amarras da sacralidade em que se encontrava até então. Por estar afastado da religião se permitiu escrever de forma livre. Com a língua sagrada ele inova e ataca a miséria dos judeus, mas não a religião em sua essência. Em sua sátira ele ri acima de tudo da pobreza espiritual em que os judeus se encontravam no Leste da Europa e da penúria econômica em que viviam confinados naquele território como prisioneiros do regime czarista. Naquela época a língua hegemônica era o russo e por isso ele também dialogava com essa língua aproximando-se do povo com o intuito de instruir os judeus pobres tentando elevá-los culturalmente. Mêndele não abandonou totalmente a incrustação de termos bíblicos em seus textos mas seu mérito foi dinamizar a língua para poder expressar a realidade de sua época, desamarrando o hebraico da prisão em que este se encontrava no final do século XIX.

Mêndele iniciou o caminho literário ao publicar seu primeiro artigo intitulado Michtav al dvar hachinuch (Uma carta sobre o caminho da educação) que foi publicado no periódico Hameguid $^{5}$, o primeiro jornal em língua hebraica da Europa Oriental em 1857. Publicou outros artigos referentes à educação hebraica no jornal Hamelitz ${ }^{6}$ em 1861 onde pregava a necessidade de instruir os jovens judeus com educação laica e inseri-los nas ciências naturais. Em 1867 participou da edição do jornal hebraico Hatsfira ${ }^{7}$ onde publicou seus escritos literários. Mêndele estava convencido que a nova literatura hebraica devia falar ao coração do povo e tratar de sua vida cotidiana. Seu primeiro romance em hebraico Limdu heitev (estudem direito) foi publicado em 1862. Em 1868 publicou Haavot veabanim (Os pais e os filhos). Em 1865 editou em ídiche o romance $O$ pequeno homenzinho. Até 1886, publicou sua obra em ídiche, dado o número reduzido de leitores capazes de ler hebraico.

\footnotetext{
${ }^{5}$ Hameguid foi o primeiro jornal em hebraico a aparecer na Europa Oriental. Ele circulou entre os anos de 1856 e 1903 primeiro como semanário e depois como jornal diário. Foi publicado inicialmente na cidade de Lyck na Prússia e depois a redação foi mudada para Berlin, Cracóvia e Viena. Seu primeiro editor foi Eliezer Lipman Zilberman entre 1856 e 1880, e o primeiro número do jornal foi publicado em junho de 1856. O segundo editor foi David Gordon que usou o jornal para difundir e apoiar o movimento dos Chovevei Sion (os amantes de Sion) e da colonização judaica na Terra de Israel.

${ }^{6}$ Hamelitz semanário publicado na Rússia entre 1860 e 1904 em iídiche e hebraico. Circulou durante um período também como jornal diário. Foi a primeira publicação jornalística em hebraico a ser publicada na Rússia. A primeira edição apareceu em Odessa em 29 de setembro de 1860 e o primeiro editor do jornal foi Aleksander Tsaderboim. Em 1893 a redação foi transferida para a cidade de São Petersburgo onde foi editado até 1904. Entre seus colaboradores aparecem figuras de destaque no movimento da Hascalá no país e alguns líderes sionistas. Colaboraram com o jornal entre outros: Yehuda Leib Gordon, Achad Haam e Moshé Leib Lilienblum.

${ }^{7}$ Hatsfirá começou a ser publicado inicialmente em 1862 como um semanário por Chaim Zelig Slonimsky em Varsóvia. Com o aumento do número de leitores, o semanário conseguiu autorização das autoridades russas que dominavam o país a ter circulação diária a partir de abril de 1886 . O semanário tinha como proposta difundir os ideais da Hascalá entre os judeus da Polônia. Com a transformação em jornal diário ele passou a contar com alguns milhares de assinantes, e em 1894 passou a ser editado por Nachum Sokolov. Este cobriu como jornalista o $1^{\circ}$ Congresso Sionista realizado na Basiléia e tornou-se posteriormente num dos líderes do movimento, fato este que aproximou a linha editorial do jornal ao Sionismo. Devido a problemas financeiros o jornal deixou de ser publicado entre 1906 e 1910. Em 1917 o jornal passou a ter o apoio da Organização Sionista Mundial até ser fechado definitivamente em 1931.
} 
Mêndele volou ao hebraico de forma inovadora com o conto Besseter Raam (No esconderijo estrondeante) publicado em 1886 em Odessa e a traduzir seus romances e escritos do ídiche para o hebraico. Foi neste período que recebeu o pseudônimo Mocher Sfórim em alusão a um pequeno mascate que ia de aldeia em aldeia, personagem comum em sua obra, e que vai descrevendo de forma irônica a situação social e econômica de extrema precariedade em que os judeus se encontravam então na Área de Residência. Seu mérito foi elevar o ídiche literário e ao mesmo tempo incentivar o uso do hebraico no ambito da literatura não religiosa. Como mostra Nancy Rozenchan, o papel desempenhado por Mêndele em pról das duas línguas foi de grande valor:

Ao se dirigir para o ídiche de Dos kleine mêntshele (a língua falada pelas pessoas comuns) e ao retornar vinte anos mais tarde para o hebraico, Abramóvitsh deu início a duas guerras que demandaram dele bastante esforço; ele as venceu com galhardia, e proporcionou às duas línguas e aos seus falantes, escritores e leitores, todos os instrumentos necessários para suprir as necessidades de comunicação escrita de alto padrão, que seriam fundamentais para o desenvolvimento das respectivas literaturas em sua época e posteriormente. ${ }^{8}$

Mêndele foi o primeiro a descrever na literatura hebraica a dura situação vivenciada por seu povo ameaçado constantemente por pogroms e perseguições. Desta forma, realismo, sátira social e alegorismos caracterizam sua obra. Ao mesmo tempo em que criticava os vícios da paupérima sociedade judaica diaspórica, demonstrava vontade em dirimir o sofrimento de seu povo. Sua obra tem como cenário alguns lugares especiais tais como: Batalon (a aldeia dos vagabundos ou preguiçosos), Kabtsiel (a aldeia dos mendigos) e Kissalon (palavra que se assemelha a Kishalon, ou seja, colapso, ou ainda poderia ser a cidade dos bobos ou dos que se negam a enxergar a realidade). Estes lugares se tornaram cenários da experiência do mundo judaico das pequenas aldeias no Leste da Europa descritos em suas obras.

O conto Besseter Raam ${ }^{9}$ (No esconderijo estrondeante) publicado em 1886 tem início justamente numa aldeia chamada Kissalon, que segundo Mêndele, aludia ou fazia referência à Área do Assentamento no qual os judeus estavam confinados. Assim, Kissalon era na verdade Kishalon, de forma irónica, um colapso, um fracasso. O narrador do conto é um viajante que se propõe a contar sobre os judeus daquele lugar, sua existência, suas vestimentas, sua forma de comportamento, seu pensamento, seus velhos e arcaicos costumes. Kissalon para o narrador, é uma aldeia judaica típica em todos os detalhes: sua casas são humildes e curvadas e por dentro das humildes casas há somente uma cama, a mesa e a bacia para lavar as mãos. E quando os policias do local chegavam com a intenção de incomodar, a regra era a mesma e repetida em todas as aldeias: se colocava em suas bocas vinho e uma fatia de chalá de Shabat e também peixes recheados e com a barriga dos algozes cheia, a vida dos pobres judeus

\footnotetext{
${ }^{8}$ ROZENCHAN, Nancy. Apresentação. In: SFÓRIM, Mêndele Môikher. O Homenzinho. São Paulo: Humanitas, 2012, p. 15.

9 O termo Besseter Raam aparece na Bíblia no livro dos Salmos, capítulo 81:8 "Batzará karata vaachaltsechá eenchá besseter raam evchanchá al mei merivá sela" (Na angústia clamaste e Eu te livrei; com voz de trovão te respondi e provei-te junto às águas de Merivá"). O conto Besseter Raam está disponível em: http://benyehuda.org/mos/beseter_raam.html <Acesso em 30/09/2012>.
} 
voltava à aparente normalidade. E quando um dia chegou ao local a noticia da aproximação de um ilustre visitante estrangeiro, toda a cidade se enfeitou e se preparou para sua chegada de forma subserviente, e o local passou a se assemelhar a "uma noiva que se prepara para a chegada de seu amado".

A aldeia aos olhos do narrador era feia, mas bonita aos olhos de seus humildes moradores judeus. Para os kissalonim, os moradores do local, aquela aldeia era louvada em palavras e atos. Eles eram tão fiéis à cidade que todo aquele que os conhecia de longe, os identificava como habitantes daquele lugar em corpo, na sua alma e na sua existência. Os kissalonim não tinham muita preocupação com a limpeza nem com a aparência elegante. Os ares da modernidade e as tendências da moda vindas do Ocidente, não lhes causavam qualquer impressão. E se por acaso alguma influência chegava à cidade desde Paris, os alfaiates imediatamente se ocupavam em dar àquela tendência estrangeira e estranha um nítido ar judaico, pois Kissalon não estava propensa a aderir às tendências da moda, muito menos às que vinham da longínqua Paris. Mêndele descreve as roupas de cima dos homens, todas elas desleixadas e antiquadas e pede aos leitores que eles imaginem o estado em que provavelmente se encontravam as roupas da parte inferior. As mulheres do lugar por outro lado, tomavam o maior cuidado com sua aparência mas estavam submetidas às rigorosas leis da Halachá que lhes determinavam como e o que deviam vestir e esta imposição valia, segundo o narrador, "para as mulheres ilustradas e para as idiotas, para as bonitas e para as feias, para as jovens e para as velhas" (p. 3).

Após descrever as pessoas e sua aparência, Mêndele, irónico, diz: "Eis que foi levantado o telão e o espetáculo está prestes a começar, assisatam e vejam meus senhores” (p. 3). E o espatáculo conforme descrito por Mêndele tem início com a proximidade do dia do Shabat. Um dos moradores da aldeia é o ilustre cocheiro Azriel, um típico representante do local, que por seis dias trabalhou arduamente com seu cavalo, mas no sétimo dia, ele se alegrou na companhia de seus filhos e de sua esposa. E além de adultos simplorios havia na cidade uma grande massa de crianças e elas são retratadas da seguinte forma:

As crianças de Kissalon, para todos os efeitos são como velhos judeus, em suas vestimentas, em sua tristeza, em suas preocupações, medos e cuidados tomados e que estão gravados em seus rostos, e mesmo que de pequena estatura e sem barbas, eles não discutem e nem brigam. E as meninas kissaloniot, parecem velhas judias, e isto pode ser distinguido pelo modo como falam, como se comportam e pela maneira submissa com que reconhecem sua posição naquele lugar. São como velhas também pela paciência que demonstram e até pela sua sabedoria. Eles são pequenos, crianças sem infância, um espetáculo triste e terrível que quebra os corações e abala os espíritos, que desperta repulsa e ao mesmo tempo misericórdia. Crianças sem infância são como plantas artificiais que enfeitam as cabeças das mulheres. (p. 4)

Ao concluir a descrição dos judeus do lugar, o narrador diz que o espetáculo acabou e o telão é baixado e então ele passa a descrever o comportamento daqueles mesmos judeus. Ao descrever o caráter daqueles moradores, o narrador se mostra ainda mais crítico e diz que pela sua natureza, os kissalonim se caracterizam por possuir um espírito baixo: eles são envergonhados e fogem das honras. Ele diz que em relação aos outros judeus eles se mostram 
firmes e até ousados mas quando é preciso enfrentar os outros povos, a situação muda e para todos os efeitos, seu espirito e coragem caem por terra e até perante os mais humildes dos gentios eles se mostram submissos e insignificantes. Se dentro de suas sinagogas eles discutem nas festividades, e em certas ocasiões brigam entre si arrancando as peiot e barbas uns dos outros na disputa por subir ao púlpito, a fim de realizar a leitura da Torá, por outro lado, eles são incapazes de se mostrar dignos perante os não judeus. Por isso os gentios riem daqueles judeus e zombam dizendo que das dez medidas de força e coragem que o Todo Poderoso deu ao mundo, a cidade de Kissalon tomou para si nove medidas, e que cada um dos judeus daquele lugar pegou para si essa coragem e a força, mas que ela é invisível e por tanto, motivo de zombaria.

Dentro de Kissalon, os moradores são seguros de si mesmos e consideram-se sábios e instruídos a tal ponto que: "A instrução em Kissalon é o início e o fim de todas as sabedorias, não existe outra forma de sabedoria além daquela, e o morador daqui é um sábio, pois ele sabe tudo e não há além dos kissalonim quem seja mais sábio e instruído do que eles" (p. 6). Mas quando um sábio kissalonita sai da Área de Residência, ele perde toda a coragem e a ousadia. $\mathrm{Na}$ cidade há profissões que são únicas segundo é claro, a crença do lugar. $\mathrm{Na}$ aldeia encontram-se os melamdim (professores), os shadchanim (arranjadores de casamentos), os comerciantes, os que emprestam dinheiro a juros, os batlanim (os que somente falam e não trabalham), os cantores rituais, os rabinos, os juízes, os açougueiros rituais, os padeiros, os redatores de jornais e até os que vendem livros, e por último os pobres e os mendigos, personagens presentes nas aldeias e no folclore judaico e em muitas das narrativas de Mêndele.

Apesar do trabalho e do esforço da maioria, a miséria impera em todo lugar e mesmo com suas inúmeras profissões, o narrador afirma que os kissalonim não têm sorte. $\mathrm{O}$ mesmo diz a este respeito que: "sentar com eles é algo extremamente agradável por que não existem entre os membros de todas as nações do mundo, pessoas mais preparadas para serem pobres, que sabem e entendem como existir e persistir na sua insignificância e miséria como os kissalonim" (p. 8). Mêndele critica seu povo que se recusa a aceitar o que acontece a seu redor e não quer ouvir. Eles acham que nada de pior poderá lhes ocorrer, pois Deus estará sempre a seu lado e lhes trará proteção. Levemente decepcionado, o narrador se dirige a Deus e clama:

\begin{abstract}
A estes teus filhos, a este teu povo Casa de Israel, eu vim para em pé contar-lhes os acontecimentos dos lugares nos quais eles habitam, mas eles tentam silenciar- me com seus gritos para que minha boca não fale nada que eles não queiram escutar. Por isso lhe peço Senhor do Universo, que Tu os entendas, para que eles sejam capazes de reconhecer o que acontece, que vejam sua situação e sejam capazes de silenciar e ouvir. (p. 9)
\end{abstract}

No entanto, um dia ele próprio narrador foi atingido pelo azar quando seu cavalo, aquele que era amarrado à carroça e que carregava os livros que ele ia vendendo entre as aldeias do lugar seu único bem foi levado por um estranho, e ele próprio que zombava da covardia de seu povo, tentou salvá-lo com a força das palavras, pois como todos os judeus, ele também carecia de força física, a única força que ele podia demonstrar era a força da persuasão, mas todo aquele esforço foi em vão e ele próprio, o crítico daquele mundo, passou a ser segundo 
suas próprias palavras, um batlan, um desocupado. E aí ele que antes criticava os outros, escuta a voz interior que lhe diz: "Se fortalece Mêndil e fala, por que você se comporta como um golem?" (p. 10). É nesse momento que o narrador se solidariza ao final das contas com seus personagens. Se antes os criticava, agora em parte os entende quando diz: "É difícil ver as lágrimas de um homem atormentado quando ele está triste e chora; mas é mais difícil ainda vê-lo chorando as escondidas, mas demonstrando alegria quando se encontra perante os outros" (p. 11).

Mêndele se revolta diante o sofrimento eterno de seu povo que insiste em demonstrar alegria quando é tão odiado e desprezado. Muitos de seu povo limitam-se a lamentar, ninguém é capaz de agir, todos vivem fazendo de conta que está tudo bem e que ficará tudo bem. O narrador resume a existência dele próprio e de seu povo e diz:

Nossa existência se apoia sobre o vazio e nos sustentamos graças a milagres e eventos sobrenaturais. A obtenção de nossos alimentos é tão dificultosa como foi a abertura do Mar Vermelho e nós louvamos a Deus por nos dar uma fatia de pão com sal, pois graças a isso, não morremos de fome. (p. 13)

Quando a questão da eterna miséria judaica foi colocada em debate no Beit Hamidrash, a casa de estudos, os simplistas disseram que era preciso se conformar com os desígnios divinos:

Nós não podemos fazer nada, sempre fomos pobres e a obtenção de alimentos para nós
foi tarefa árdua, e apesar de tudo, com a miséricórdia divina que paira sobre nós, não
morremos e nem nossos filhos, e nós estamos todos aqui vivos. E se nos ocorre uma
tragédia, isso se deve apenas a uma coincidência, pois nossos olhos se dirigem a Nosso
Pai que está nos céus e Ele nos dá força e coragem para aguentar o sofrimento e nossas
desgraças e assim, viveremos e seremos merecedores de dias melhores. Passarão os dias e
o mundo retomará seu rumo e tudo voltará a seu lugar em paz. Mas até esse dia chegar,
este é nosso conselho: Fé! Devemos rezar diante de nosso Deus que está nos céus, jejuar e
pronunciar Tehilim (Salmos) e slichot (pedir perdão). (p. 16)

A opinião acima é rebatida pelos que rejeitavam esse olhar simplista e eles repreendem os simplorios dizendo: "Vocês confiam suas vidas a milagres e estão testando a Deus. Se continuarmos aqui sentados e não fizermos nada, então morreremos de fome e se não formos por nós mesmos então quem o fará por nós?” (p. 16)

Mas a vida continuava seu rumo num mundo em transição. Alguns abandonaram aquele lugar para se espalhar por outras terras. Ao narrador, porta voz da consciência, resta apenas elevar suas súplicas aos céus e rezar silenciosamente para que a redenção venha ainda em seus dias. Ele, narrador, conseguiu comprar um novo cavalo e uma carroça para nela colocar velhos e novos livros. A ele cabe continuar vagando pela Área de Residência observando, narrando, lamentando, mas também encorajando seu povo.

Mêndele descreve desta forma, um mundo a parte, um verdadeiro microcosmo isolado, uma sociedade que sofria restrições legais de todos os tipos, mas que acreditava na redenção. Mêndele faz este percurso numa época e em que a língua na qual ele narra sua história era compreensível para poucos, mas aqui está seu grande mérito. Para todos os efeitos, ele tenta 
emitir um grito que está engasgado, mas a voz do trovão permanece escondida, os ouvidos dos pequenos homenzinhos não estavam dispostos a escutar o que vinha do mundo para além daquela aldeia. 


\section{Referências}

ASLANOV, Cyril. A Literatura como motor da modernização da língua hebraica, in WebMosaica, Revista do Instituto Cultural Judaico Marc Chagall. Volume 4, n. 2, 2012.

EFRATI, Nathan. Tchyat halashon hayivrit veatnua hatsionit (The Zionist Movement and the Revival of Hebrew) Leshonenu Laam, Volume XLVIII, n 3, Jerusalém, The secretariat of the Academy of the Hebrew Language, 1997.

. Milashon yechidim lilshon umá - hadibur hayivri beEretz Israel bashanim 1881 - 1922. (De lingual particular a lingual nacional - a fala hebraica na Terra de Israel entre os anos 1881 - 1922). Jerusalém, The secretariat of the Academy of the Hebrew Language, 2003.

HARAMATI, Shlomo - Dibur ivri bitkufat haascalá (A fala hebraica à época da Haskalá) in, Leshonenu laham, Volume 39, edição de número 5, Jerusalém, editora da Academia da Língua Hebraica, 1989.

HERZL, Theodor. O Estado Judeu. Rio de Janeiro, Gramond, 1998.

MAPU, Abraham. Ahavat Tsion. Disponível em:

http://benyehuda.org/mapu/ahavat_zion_complete.html <Acesso em 30/09/2012>

RABIN, Chaim. Chekrei lashon: Assufat maamarim balashon hayvrit ubeachyotea (Linguistic Studies: collected papers in Hebrew and Semitic Languages). Jerusalem, The Academy of the Hebrew Language, 1998.

SFÓRIM, Mêndele Mocher (ABRAMÓVITSH, Shólem Yákov). Besseter Raam

(No esconderijo estrondeante) Disponível em: http://benyehuda.org/mos/beseter_raam.html $<$ Acesso em 30/09/2012>. 